\title{
COPA DO MUNDO DE 2006: O QUE ELAS ESCREVERAM NA FOLHA DE SÃO PAULO
}

\author{
Raquel Da Silveira*
}

\section{RESUMO}

Este trabalho consiste em uma análise das publicações da Folha de São Paulo, escritas por mulheres sobre a Copa do Mundo de 2006. As reportagens foram divididas em três grupos, nos quais se identificou que existem diversas maneiras das articulistas participarem desse momento de Copa. Se o nacionalismo é o argumento destacado pelos autores que estudam o futebol para explicar a participação das mulheres nesse universo, podemos dizer que, nesse estudo, ele foi tão requisitado quanto outros aspectos identitários presentes nas vidas dessas articulistas. Elas vivenciaram a Copa da Alemanha, explicitando constantemente suas diversas formas de ser mulher.

PALAVRAS-CHAVES: Copa do Mundo - nação - mulher

\section{INTRODUÇÃO}

\begin{abstract}
cabamos de vivenciar um período de Copa do Mundo $^{1}$ no qual Atelevisões, rádios, jornais e revistas dedicaram grandes espaços a esse evento. ${ }^{2}$ Peças publicitárias foram elaboradas, contribuindo para uma overdose do tema. Na mídia se percebeu que especialistas e também não-especialistas em futebol foram convocados a expressar suas opiniões sobre o assunto. Épocas de Copa do Mundo são momentos em que a prática do futebol ultrapassa, visivelmente, ${ }^{3}$ os limites do campo esportivo e são re-apropriadas, ganhando inúmeras releituras. São ocasiões em que afirmativas, crenças, valores e/ou mitos são elaborados e reforçados no que tange não apenas ao universo futebolístico, mas também a outros campos da sociedade.
\end{abstract}

* Mestranda do Programa de Pós-Graduação em Ciências do Movimento Humano pela Universidade Federal do Rio Grande do Sul e bolsista da CAPES. 
Para se ter uma idéia, Édison Gastaldo e Simoni Lahud Guedes, ao organizarem o livro Nações em campo: Copa do Mundo e identidade nacional, fazem a análise de uma dessas afirmativas que não apenas estão presentes, mas fazem sentido para uma parte significativa de pessoas da nossa sociedade. Para Gastaldo e Guedes (2006, p. 9), é importante questionar a "lógica tão facilmente naturalizada" disso que está sendo dito:

tendo nascido no Brasil, nossa pátria nos faz sambistas, malandros, esperançosos, bem-humorados e, é claro, bons de bola. E, mais do que isso, nos opõe e nos diferencia dos que nascem em outras nações e pátrias, pretensamente herdeiros de outras habilidades e características. Será? (GASTALDO; GUEDES, 2006, p. 9)

O objetivo desse trabalho é, também, questionar uma dessas afirmações: será que as mulheres não estão presentes no universo do futebol? Ou, ainda, será que no futebol "as mulheres fazem o papel de coadjuvante, a mãe que lava os uniformes, a irmã que limpa as chuteiras, a namorada que prepara e serve as bebidas etc." (MOURA, 2005, p. 140)?

Para responder a essas perguntas e questionar a validade dessas afirmativas, crenças e idéias que são (re)criadas e reforçadas durante esse período que abarca jogos, analisamos as reportagens e crônicas escritas por mulheres sobre a Copa do Mundo de 2006 no jornal Folha de São Paulo.

\section{FOLHA DE SÃO PAULO: POR QUE ESTE JORNAL?}

Delimitando esse trabalho a um tipo específico de futebol, ${ }^{5}$ qual seja aquele das Copas do Mundo, percebe-se que são diversas as pesquisas desenvolvidas nesse campo. Além disso, muitos dos pesquisadores dessas investigações recorrem aos meios midiáticos como uma das possíveis maneiras de interpretar esses momentos de Copa ${ }^{6}$ Contudo, torna-se explícito que, apesar da mídia ser um meio utilizado para esse fim, devemos ter certo cuidado com sua utilização.

Os veículos de comunicação possuem padrão próprio de apresentação das matérias, "fabricam para seu público uma apresentação e uma representação dos problemas" (SOUZA, 2003, p. 90). Por unila- 
teral, impossível a neutralidade. Souza (2003), ao realizar um trabalho sobre a participação da Folha de São Paulo na discussão de algumas mudanças ocorridas no futebol brasileiro em 1997, constrói um tópico dedicado unicamente para falar do jornal em questão, contextualizando-o nos dias atuais. ${ }^{7}$ Diversos elementos são apresentados pela autora para justificar que, a partir do projeto editorial instalado em 1984, "a norma é escrever no "padrão Folha"" (SOUZA, 2003, p. 73). Além disso, a identidade do jornal se constrói, principalmente, através da "delimitação dos consumidores da Folha de São Paulo em termos de estratos sociais e de abrangência regional" (SOUZA, 2003, p. 72).

É nesse sentido que consideramos importante alguns cuidados ao trabalharmos com meios midiáticos em discussões acadêmicas.

Torna-se claro que o jornal utilizado nesse trabalho é feito para determinado grupo de pessoas e, portanto, as informações nele contidas estão dentro de um padrão que atende, de alguma forma, ao interesse dessas pessoas. ${ }^{8}$

Logo, ao utilizar as publicações escritas pelas articulistas da FoIha de São Paulo sobre a Copa do Mundo de 2006, não temos pretensões de entender como as mulheres, de forma geral, participam desse momento. Apenas delimitaremos esta análise ao grupo daquelas que estão inseridas nesse público, atendido por esse jornal.

A coleta de reportagens teve início no dia 18 de maio e encerrou-se em 20 de julho de $2006 .{ }^{9}$ Nesse período, foram publicadas 109 matérias, sendo 63 no caderno específico de esportes ${ }^{10}$ e 46 em outros cadernos que compõem a edição do jornal Folha de São Paulo. ${ }^{11}$

\section{A CATEGORIZAÇÃO DAS REPORTAGENS}

"Copa do mundo alavanca o desempenho econômico" (LAGE, 2006, p. B13); "Favoritismo x Já Ganhou” (SONINHA, 2006a, p. D3); "Copa do mundo inspira coquetéis tropicais" (BOTELHO, 2006, p. E5); “Onipresença ameaça ataque de Ronaldinho na mídia" (MATTOS, 2006, p. B10); "Jogos mal começaram, mas já irritam a tribo dos que odeiam o campeonato" (FERREIRA, 2006, p. C4); "País exalta Ronaldinho e transfere o favoritismo" (MARREIRO, 2006b, p. D7). Esses são alguns títulos das reportagens publicadas por mulheres na Folha de São Paulo que envolvem a Copa do Mundo de 2006. 
Falaram de aspectos do jogo do futebol, ${ }^{12}$ estendendo-se aos assuntos mais diversos que elas relacionaram com a Copa do Mundo. ${ }^{13}$ Não deixaram de fora nem suas próprias experiências durante esse período. Dessa forma, a pergunta "Será real a afirmativa corrente de que as mulheres não estão presentes no universo do futebol?" é respondida negativamente. ${ }^{14}$ É visível que, pelo menos nesses momentos, elas participam. Contudo, isso não é novidade, pois essa constatação já foi feita por alguns pesquisadores. Por exemplo, Damo (2006a, p. 41) afirma que, apesar de as mulheres não manterem proximidade com o universo futebolístico durante $o$ período entre Copas, há "adesão massiva do público feminino" nas Copas do Mundo, e esta acontece, principalmente, devido à equipe de futebol representar a nação. ${ }^{15}$

Nas reflexões desse autor, está presente a idéia de que o sentimento de nacionalismo, na época de Copa do Mundo, é constantemente requisitado não apenas por quem se identifica com futebol, mas também por quem se percebe integrante de uma identidade nacional.

Dessa forma, surge outro questionamento a ser feito, pois já está confirmado que as mulheres estão presentes no universo do futebol durante as Copas. Resta saber de que maneira isso acontece. Como algumas mulheres vivenciam esse momento? Como a nacionalidade se faz presente nessa vivência?

Apesar de toda a diversidade encontrada nas publicações, classificamos três grupos para categorizar as reportagens: no primeiro, estão as reportagens em que a Copa do Mundo da Alemanha é o assunto central $;{ }^{16}$ já as do segundo possuem a característica de atribuir à Copa espaço secundário, pois o tema em destaque acaba ultrapassando o universo futebolístico e até mesmo esportivo para abordar os mais diversos assuntos inseridos no nosso cotidiano; ${ }^{17}$ finalmente, no terceiro grupo, incluímos aquelas que não se enquadravam em nenhum dos anteriores. Em parte dessas últimas, era destacado algum episódio da Copa, embora outros temas, como, por exemplo, a família, fossem enfatizados. As reportagens desse último grupo apresentam a característica de relatar experiências das próprias articulistas em relação a algum fato ou momento desse evento esportivo. ${ }^{18}$ 


\section{OS TRÊS GRUPOS DE REPORTAGENS E SUAS POSSÍVEIS RELAÇÕES COM A NAÇÃO}

Discussões sobre nação estão muito presentes no campo das Ciências Sociais, não cabendo nesse artigo explorar esse assunto. No entanto, consideramos necessário destacar alguns pontos sobre o tema, já que o nacionalismo é um dos argumentos correntes, utilizados para explicar a participação das mulheres nas Copas do Mundo.

Podemos dizer que existem algumas idéias centrais para nos aproximarmos da noção de nação: ser processo recente; a identidade nacional; o regionalismo; as memórias (pessoal, coletiva e nacional) e as tradições. As nações surgem "na Europa a partir do final do século XVIII" (OLIVEN, 2006, p. 20), podendo ser consideradas fruto de mais uma das tradições inventadas, como teoriza Hobsbawm (1984). Apesar de possuir fronteiras geopolíticas e culturais delimitadas, são os atores sociais que decidem o que faz e o que não faz parte de determinada nação. Logo, identidade nacional nos faz pensar em conflitos ${ }^{19}$ que nos mostram que tanto a memória como a identidade nacional não podem ser interpretadas de uma única forma, sendo essa última, "na verdade, uma construção cultural e ideológica, uma seleção, um ordenamento de determinadas lembranças" (ORTIZ, s.d., p. 78). Mesmo assim, fica evidenciado que a identidade nacional possui certa preeminência se comparada às diversas identidades culturais presentes em uma nação. Ela se configura como uma identidade que possui status maior que as outras. Contudo, devemos ser cuidadosos no trato com tal afirmação, pois pode nos levar ao engano e esconder outras possíveis reflexões. Por exemplo, com o processo de globalização, identidades culturais extrapolam as fronteiras geográficas. Ortiz nos traz o exemplo da juventude que, para ele,

só pode ser entendida quando situada no horizonte de mundialização - $t$-shirt, tênis, calças jeans, ídolos de rock, surf, são referências desterritorializadas que fazem parte de um léxico, de uma memória juvenil internacional-popular (ORTIZ, s.d., p. 85).

Refletir sobre o exemplo trazido pelo autor, tendo como referência nosso cotidiano, nos remete a algumas questões que acabam mostrando que os referenciais identitários da juventude apresentam-se, pelo 
menos em grande parte do tempo, mais fortes que aqueles constituintes de uma identidade nacional. Por exemplo, se os questionamentos forem em relação à forma como um jovem se apropria do hino nacional de seu país. Essa forma é mais significativa e está mais presente no seu diaa-dia do que a maneira com que ele se apropria das músicas que fazem parte da sua identidade jovem? Qual o valor simbólico da bandeira nacional para um jovem? Será que esse valor é maior que aquele atribuído às camisetas de bandas de rock que ele veste?

Dessa maneira, percebemos que nos dias de hoje não se pode pensar impunemente que a identidade nacional se sobressai das outras. No entanto, também seria reducionista acreditarmos que a memória, o hino, a bandeira e todos os outros símbolos que constituem uma nação não fazem sentido no contexto atual. Ao mesmo tempo em que podemos identificar facilmente no nosso cotidiano o exemplo da identidade jovem trazida por Ortiz, podemos também dizer que, em determinados momentos da nossa sociedade, os significados atribuídos aos símbolos nacionais ganham importância diferenciada que nos remete ao sentimento de pertencer à nação. Um dos momentos em que isso pode ser identificado se dá via esporte, em especial em competições internacionais, como as Olimpíadas e a Copa do Mundo de futebol masculino.

Nessa perspectiva, olhando para as reportagens aqui analisadas, veremos que em algumas delas a identidade nacional realmente está presente. Contudo, não podemos afirmar que essa seja a única identidade requisitada pelas mulheres para escreverem sobre a Copa. Nem mesmo podemos falar que é a identidade com maior destaque. Há reportagens em que as articulistas, além de não se referirem aos aspectos do nacionalismo para fazer referência à Copa, evidenciam outras identidades culturais de que compartilham.

Ao observamos o primeiro grupo de reportagens, cujo tema central é a Copa do Mundo, é visível que o sentimento de nacionalismo seja freqüentemente requisitado. Mesmo que as articulistas não tenham escrito sobre a seleção brasileira, ${ }^{20} \mathrm{o}$ aspecto da alteridade está presente para nos diferenciar das outras seleções e nações. Nas reportagens de Flávia Marreiro, por exemplo, é constante o uso de "uma alteridade privilegiada: Brasil/Argentina" (GUEDES, 2006, p. 131). ${ }^{21} \mathrm{Na}$ reportagem "Buenos Aires vibra e dá fim à humildade", ${ }^{22}$ 
Flávia Marreiro (2006a, p. D7), ao falar da comemoração dos torcedores argentinos, destaca como estes se referiam ao Brasil: "Os argentinos, como Alcides, esqueceram a humildade que usavam até agora para falar da Copa: que venha o Brasil, repetiam".

Mariana Barros também escreveu suas reportagens com essa característica. Realizando a cobertura dos fatos que envolviam a seleção francesa, ela utilizou como referência de comparação a seleção brasileira. ${ }^{23}$

Ainda nesse caminho, a questão da nacionalidade também foi muito "requisitada" no terceiro grupo de reportagens, ${ }^{24}$ mais especificadamente naquelas publicadas por Soninha, Bárbara Gancia, Agathe Giraud, Silvia Bittencourt e Bia Abramo que simplesmente falam sobre os jogos, jogadores e jogadas da Copa.

Após uma semana da derrota brasileira na Copa, Bárbara Gancia publica a crônica "A seleção é a cara do Congresso" no dia 07/07/2006, expressando seu descontentamento com os jogadores que compunham a seleção brasileira, principalmente devido à falta de empenho deles perante a nação.

Começou tudo errado e deu no que deu. Quem ainda se lembra do momento em que Cafu ergueu a taça na Copa de 2002? Na época, achamos lindo o tributo prestado à mulher, Regina.

Mas, hoje, conhecemos melhor o individualismo e a cara-de-pau de certos jogadores, que foram à Alemanha pensando exclusivamente no próprio umbigo. E temos noção de que Cafu não poderia ter sido tão egoísta. Afinal, ao levantar a taça, ele não estava ali como marido da Regina, mas representando seus companheiros e seu país (GANCIA, 2006, p. C2).

Soninha também publica suas crônicas expondo críticas, dúvidas e opiniões sobre a seleção brasileira de forma muito objetiva:

No lugar do Parreira, o que faria eu? Humm...

Faria uma tentativa com Emerson, Juninho e Zé Roberto; Kaká, Ronaldinho e Ronaldo (talvez com o ponto-e-vírgula depois de Kaká). Liberando Zé Roberto e Juninho para, alternadamente, jogarem com os laterais e avançarem, cada um a seu modo, no ataque. Robinho poderia entrar a qualquer momento no lugar de Zé Roberto; Adriano, no de Ronaldo (SONINHA, 2006b, p. D7). 
Esse trecho, acima citado, foi publicado antes do início da competição quando o técnico da seleção brasileira estava testando as possibilidades de quais jogadores poderiam compor o time titular. ${ }^{25}$

Já após os três primeiros jogos do Brasil na Copa, Soninha publica a crônica "E agora, Parreira?", questionando se, após esses jogos nos quais várias mudanças de jogadores foram realizadas, o técnico da seleção iria continuar com o mesmo time inicial da competição:

não tenho certeza de que a defesa tenha piorado, mas não há no mundo quem possa negar que o ataque melhorou muito. Tabelas, pivôs, lançamentos, o Brasil expôs seus repertórios com garbo.

Não é possível que, depois dessa demonstração, toque de bola - o que Parreira, teoricamente, espera de suas equipes -, o time volte à formação anterior. O primeiro consenso nacional deve ser respeitado: o ataque funciona melhor com Robinho e um centroavante - e Ronaldo, em quem eu não acreditava mais, deve deixar Adriano no banco (SONINHA, 2006d, p. D7).

Queremos destacar que o objetivo, aqui, não é analisar se as opiniões dadas por Soninha são boas ou não, iriam ou não melhorar o time. O importante é perceber como ela se integra a esse momento. É ver que ela, ao participar dos momentos da Copa de 2006, discute sobre os jogos, os jogadores, as jogadas, opina sobre a escalação, reivindica mudanças etc.

Assim, podemos dizer que a forma como o nacionalismo foi requisitado nessas reportagens diferencia-se daquela maneira feita no primeiro grupo. Se o conceito de alteridade nos ajudou a compreender as publicações que têm a Copa do Mundo como tema central, ele não é suficiente para entendermos as reportagens das articulistas do terceiro grupo acima citadas. Elas, além de reforçarem as diferenças entre seleções, também recorrem a outras formas de requisitarem o sentimento de nacionalismo.

No entanto, apesar das diferenças, as reportagens analisadas até o momento envolveram questões que nos remetem ao nacionalismo. Fica evidente que a identidade nacional foi requisitada e reforçada por parte das mulheres que escreveram sobre a Copa do Mundo. Entretanto, existem publicações que não nos remetem à identidade nacional, mas, sim, para outras identidades culturais e categorias de análise. 
No segundo grupo de reportagens, onde a Copa da Alemanha acaba ficando em um lugar secundário, por exemplo, as articulistas não exploram os aspectos do nacionalismo, mas aqueles próximos a suas especificidades profissionais.

No dia 04/06/2006, foi publicada a matéria "Para não dizer que só falei das flores" que contém dois artigos: um, escrito por Mariana Lajolo, "O espinho do racismo"; e o outro, por Heloísa Reis, "O cravo da violência". No primeiro artigo, Mariana Lajolo realiza uma entrevista com um especialista em racismo. ${ }^{26}$ Ela questiona o racismo no futebol e como ele será tratado na Copa.

Já Heloísa Reis ${ }^{27}$ escreve sobre violência urbana nos dias de jogos de futebol. Ela apresenta dados das maiores violências acontecidas em estádio de futebol no Brasil e no mundo. Para ela,

Uma das explicações das raízes da violência relacionada ao esporte pode ser encontrada na gênese e no desenvolvimento do futebol moderno, visto como ambiente de produção e reprodução de valores de masculinidade. E outra, no sistema de metabolismo social do capital.

Se levarmos em conta a primeira, não é de se estranhar que a "linha dura" dos grupos agressores seja formada basicamente por jovens de sexo masculino. Para eles, a valentia e a força são elementos necessários para o enfrentamento do inimigo (REIS, 2006, p. 9).

Fica evidente que, nos artigos de Mariana Lajolo e Heloísa Reis, as categorias exploradas para falar da Copa foram racismo, violência e gênero. Assim como as outras articulistas desse segundo grupo de reportagens, elas escrevem sobre esse evento, enfatizando aquele tema que mais dominam.

No terceiro grupo de reportagens, mais especificadamente naquele composto por Cíntia Moscovich, Clarah Averbuck, Danuza Leão, Jô Hallack, Nina Lemos e Raq Affonso, chama atenção os diversos aspectos que elas explicitam para relatar suas experiências relacionadas à Copa.

Falando a partir do papel social de filha, neta, namorada, esposa, amiga, essas mulheres, ao escreverem sobre o assunto em questão, deixam claro que esses papéis sociais não são abandonados durante esse período. Elas continuam fazendo compras, aproveitando as liquidações, não gostando e/ou não entendendo de futebol, fazendo tarefas domésticas etc. Ou seja, elas simplesmente continuam sendo as mesmas mu- 
lheres. Danuza Leão, ao falar da Copa e das diferenças entre homens e mulheres na crônica "Dois mundos", publicada no dia 11/06/2006, coloca que:

No dia em que a seleção joga, nem Simone de Beauvoir e Sartre, juntos, seriam capazes de convencer alguém de que homens e mulheres são iguais, até porque não são. Homem só consegue fazer uma coisa de cada vez; já as mulheres conseguem fazer várias ao mesmo tempo. Está acostumada a atender o telefone e abrir a geladeira - com o filho no colo - e simultaneamente dar uma olhada na televisão.

$[\ldots]$

Nenhuma atividade consegue fazer com que uma mulher se desligue totalmente do mundo; quando amamenta seu filho, talvez. Mas mesmo nessa hora ela é capaz de olhar para as unhas e lembrar que precisa ir à manicure, mandar fazer a bainha da saia e passar no supermercado (LEÃO, 2006, p. C2).

Entendo que, no trecho acima, quando Danuza Leão generaliza ao falar das diferenças entre homens e mulheres, devemos considerar que ela se refere a um determinado grupo de homens e mulheres que integram o seu convívio social. Mostra, também, como ela e algumas mulheres "são inquietas, ardentes, e não conseguem, jamais, ficar durante 90 minutos vendo 22 marmanjos correndo atrás de uma bola; conseqüentemente, não podem entender como eles ficam paralisados quando a seleção entra em campo" (LEÃO, 2006, p. C2). Além disso, nessa mesma crônica, Danuza expressa que as mulheres "o máximo que conseguem, em matéria de futebol, é discutir sobre qual o jogador mais bonito do time do Brasil". Para essa articulista, portanto, a identidade cultural que ela possui enquanto mulher não é deixada de lado nos momentos de Copa do Mundo para requisitar um sentimento de nacionalismo.

Cíntia Moscovich, para falar da Copa, na reportagem "Sono redondo", publicada no dia 28/05/2006, recorre a lembranças de infância. Ela relata como sua família assistia aos jogos:

Em épocas de Copa do Mundo, a mãe cozinhava pinhões, estourava pipocas, passava café novo. O pai fechava as cortinas para a imagem ficar melhor. Com a ala masculina da família, eu exercitava minha curiosi- 
dade - e minha preguiça. Nunca entendi como eles se fascinavam tanto com aqueles 22 jogadores briguentos, todos melecados de suor. Era a bola rolar no gramado e eu começava aos bocejos, me batendo contra o sono - mas, depois do Hino Nacional, dos pinhões e das pipocas, adormecia e só acordava quando tudo tinha acabado. Futebol, para mim, era sinônimo de barriga cheia e soneca (MOSCOVICH, 2006, p. D6).

Nessa crônica, Cíntia relata também o modo como sua família se preparou, assistiu e comemorou a vitória do Brasil sobre a Itália na Copa de $70 .{ }^{28}$ Como o Brasil ganhara, ela acordou com foguetório e viu seus familiares comemorando o tricampeonato da seleção. Conta que até o porteiro do prédio, Seu Antero, estava na sala do apartamento, prendendo na janela uma imensa bandeira do Brasil. A comemoração foi envolvente, e logo ela também estava participando da festa.

Para finalizar seu relato a escritora descreve como, nos dias atuais, ela, agora, junto a sua família, se preparam para assistir aos jogos de Copa do Mundo:

Continuo sem entender nada de futebol. Nada. Nadica. Mas, quando o Brasil joga, a televisão aqui de casa sempre está ligada, mesmo antes do Hino Nacional. Faço pinhão e pipoca. Também estendo bandeira do Brasil. Em homenagem a papai e a seu Antero, [...] pulo, xingo, digo palavrões - mesmo que meu marido diga que eu faço tudo isso na hora errada. Nem me importo, vejo o jogo de cabo a rabo.

O melhor de tudo: nunca mais adormeci (MOSCOVICH, 2006, p. D6).

O que a análise das reportagens mostra é que as mulheres vivenciam o período de Copa do Mundo de diversas maneiras. Algumas exaltam seus sentimentos de nacionalismo para falar desse acontecimento, enquanto outras remetem a elementos de outras identidades culturais das quais compartilham. O que fica claro, portanto, é que Copa do Mundo, nação e mulheres são passíveis de relações que, entretanto não acontecem sempre da mesma forma.

\section{CONSIDERAÇÕES FINAIS}

Com 109 reportagens, crônicas e pequenos comentários publicados no jornal Folha de São Paulo, escritos por mulheres sobre a Copa 
do Mundo de 2006, foi possível afirmar que elas participaram desse momento. As articulistas realizaram coberturas de acontecimentos que envolveram a Copa da Alemanha; assistiram, comentaram e criticaram os jogos; estenderam a bandeira do Brasil na janela para "homenagem a pessoas próximas" que gostavam de futebol; requisitaram o sentimento de nacionalismo; fizeram pipocas e pinhões; elegeram o jogador mais bonito em campo; criticaram a escalação do técnico Parreira e usaram conhecimentos de outras áreas para compreender algum aspecto da Copa do Mundo de 2006.

Falar que no futebol "as mulheres fazem o papel de coadjuvante, a mãe que lava os uniformes, a irmã que limpa as chuteiras, a namorada que prepara e serve as bebidas etc." (MOURA, 2005, p. 140) é simplificar as diversas maneiras como elas vivenciam e participam do universo futebolístico.

Divididas em três grupos de análise, identificamos que aquelas reportagens que tinham como tema central a Copa da Alemanha possuíam a característica de serem coberturas de acontecimentos, envolvendo seleções diferentes da brasileira. Mesmo assim, chamavam a atenção para o aspecto da nacionalidade. Foi demarcando as diferenças entre a seleção brasileira e as outras, que as articulistas reforçaram o sentimento de pertencer à nação.

No grupo de reportagens em que a Copa do Mundo esteve apenas como um dos temas abordados, verificamos que, além da variedade de assuntos, estes geralmente fizeram parte das respectivas especialidades das articulistas. Nesse grupo, dificilmente a questão do nacionalismo foi evidenciada. Categorias diferenciadas foram referidas para falar sobre o evento esportivo.

Dentre as reportagens que se constituíram em relato de experiência em relação à Copa, constatamos que, em parte delas, o nacionalismo se fazia presente. $\mathrm{O}$ sentimento de pertencer à nação foi explicitado, principalmente, por aquelas mulheres que comentavam, apoiavam ou, às vezes, criticavam os jogos, jogadores e técnico da seleção brasileira. Diferentemente, em outros relatos, as articulistas deixavam claro que não entendiam e/ou não gostavam de futebol. Elas descreveram experiências em relação à Copa, a partir de seus papéis sociais fortemente demarcados. Nos momentos de jogos, continuaram sendo esposa, namorada, amiga etc. 
As relações possíveis de se estabelecer entre Copa do Mundo, nação e mulheres são diversas. Nosso objetivo com esse trabalho, no entanto, não foi dar conta de todas elas. Centrei-me em discutir principalmente a contextualização das reportagens publicadas pelas articulistas da Folha de São Paulo onde essas relações foram evidenciadas.

Enfatizamos a importância de pensarmos o processo de globalização e suas conseqüências de forma complementar com os elementos da nação, pelo menos nos dias de hoje. Se possuímos uma identidade nacional, também possuímos outras identidades que nos possibilitam participar de diferentes contextos sociais.

O importante dessa discussão é destacar que, mesmo interpretando o processo de globalização, não como busca de uma "cultura global", mas sim como uma desterritorialização onde há uma aceleração da mobilidade no sentido de ultrapassar os limites de uma nação (ORTIZ, s.d.), o sistema simbólico que permeia e constitui uma determinada nação não apenas existe, mas perpassa inúmeros momentos da vida das pessoas. Parece fácil aceitar que o nacionalismo é tão forte nos dias atuais que a afirmativa "paramos para ver a seleção na copa" (DAMO, 2006a, p.55) é algo quase inquestionável. No entanto, penso que essa afirmativa poderia ser complementada de forma a considerar que, se paramos para ver a seleção na Copa, principalmente por nos remeter à nação, não deixamos de explicitar os valores e símbolos das outras identidades a que nos sentimos pertencentes.

Fica evidente, portanto, e requerendo mais análises, a questão: será que é o nacionalismo que faz com que as pessoas parem para ver a seleção na Copa? Nesse trabalho pôde ser observado que existiram outros fatores importantes, além do sentimento de pertencer à nação, sendo requisitados pelas articulistas da Folha de São Paulo na Copa de 2006.

World Cup Football 2006: what women wrote in Folha de São Paulo

\section{ABSTRACT}

This research work consists of an analysis of articles written by women and published in Brazilian newspaper Folha de São Paulo about the 2006 World Cup Football. The articles were divided into three categories that made it possible to identify the different ways in which women writers participated in World Cup Football 2006. If nationalism 
is the motive that is highlighted by football scholars to explain female participation in this universe, we can argue that in this research study it was as important as other identity aspects which are present in the lives of these writers. They experienced the World Cup by constantly expliciting their many ways of being women.

KEYWORDS: World Cup Football - nation - women

\section{Copa del Mundo 2006: o que ellas escribieron en la Folha de São Paulo}

\section{RESUMEN}

Este trabajo consiste en un análisis de las publicaciones del periódico Folha de São Paulo, escritos por mujeres sobre la Copa Mundial de Fútbol en 2006. Los reportajes fueron divididos en tres grupos, en los cuales se identificó que existen diversas maneras de las articulistas en participar de ese evento. Si el nacionalismo es el argumento destacado por los autores que estudian fútbol para explicar la participación de las mujeres en ese universo, podemos decir que, en este estudio, el mismo fue tan requisitado como otros aspectos identitarios presentes en las vidas de esas articulistas. Ellas vivenciaron la Copa de Alemania, explicitando constantemente sus diversas formas de ser mujer.

PALABRAS-CLAVE: Copa Del Mundo - nación - mujer

\section{NOTAS}

1 A Copa do Mundo de 2006, realizada na Alemanha, iniciou em 9 de junho e terminou em 9 de julho.

2 Na televisão, por exemplo, na Rede Globo, foram realizados programas especiais - Brasil na Copa - para avaliarem o desempenho da seleção brasileira no campeonato. Já quanto aos jornais, temos como exemplo o caderno especial que a Folha de São Paulo publicou no período da Copa do Mundo.

3 Utilizo essa expressão "visivelmente" por acreditar que existem outros momentos em que a prática esportiva é re-apropriada, ganhando significados que perpassam diferentes esferas da vida das pessoas, além daquela em que o esporte seja considerado protagonista.

4 Grifo nosso.

5 Interessante especificar que o futebol a que estou referindo nesse trabalho é o futebol espetáculo, pois nos dias de hoje temos diversas maneiras de vivenciar essa prática. Stigger (2002) mostra, em uma pesquisa etnográfica, dois grupos de praticantes de futebol (e um grupo de praticantes de voleibol) que se apropriam dessa atividade de maneira diferenciada. Esse autor identifica outros valores que ga- 
nham destaque no jogo de futebol praticado por esses grupos de pessoas, diferentes daqueles presentes no esporte de alto rendimento. Um exemplo disso se dá na categoria de análise "companheiro adversário" (STIGGER, 2002, p. 190) desenvolvida pelo autor a partir dos dados obtidos na investigação. Com isso, Stigger propõe que o mais adequado é falarmos em esportes ao invés de esporte. Nessa mesma perspectiva, mas referindo-se apenas ao futebol, Damo (2006a) vai propor pensarmos em "futebóis" e não futebol. Esse autor desenvolve sua discussão a partir das matrizes futebolísticas que, para ele, as principais seriam: "espetacularizada, bricolada, comunitária e escolar" (DAMO, 2006b, p. 9).

6 Como um exemplo, ver o trabalho: "A Pátria na 'imprensa de chuteiras': futebol, mídia e identidades brasileiras” de Édison Luis Gastaldo (2006).

7 Tendo sua primeira edição realizada em janeiro de 1960, o jornal Folha de São Paulo passou por diversas mudanças tanto de caráter organizacional quanto de políticas até chegar a sua forma atual. $\mathrm{O}$ que a autora explora nesse tópico são as diversas práxis jornalísticas que fizeram parte da trajetória do jornal, em especial em relação ao jornalismo esportivo.

8 Acredito que essas características não impeçam sua utilização como dados de pesquisa, desde que o investigador e o leitor saibam que as informações publicadas na Folha de São Paulo atendem a interesses restritos.

9 Importante destacar que, no dia 15 de maio de 2006, o técnico da seleção brasileira fez a convocação dos jogadores que iriam representar o Brasil na Copa.

10 Aqui incluo o caderno especial "Copa 2006" que circulou durante os dias da Copa do Mundo.

11 O jornal Folha de São Paulo possui os seguintes cadernos diários: Folha Brasil, Folha Ciência, Folha Cotidiano, Folha Dinheiro, Folha Esporte, Folha Ilustrada e Folha Mundo. Traz, também, os seguintes cadernos especiais de circulação nacional: Folha Imóveis, Folha Informática, Folha Equilíbrio, Folha Turismo, Folhinha, Folhateen, Mais!, Folha Veículos, Folha Construção, Empregos e Folha Negócios, e, ainda, dois especiais de circulação apenas na Grande São Paulo: Revista da Folha, Guia da Folha (esses eu não 
utilizo nesse trabalho pelo fato de haver assinado o jornal na cidade de Porto Alegre).

12 Como, por exemplo, a posição tática dos jogadores, as condições físicas dos atletas.

13 Tais como economia, moda, política, entretenimento, religião, propaganda, culinária, trânsito, saúde, gênero etc.

14 Importante destacar que, quando me refiro ao "universo do futebol", estou não apenas falando do momento do jogo em si, mas também de todos os aspectos que o envolvem, ou seja, estou me referindo ao contexto em que esse jogo está colocado. Participar do universo futebolístico, portanto, deve ser entendido como integrar, de alguma forma, esse contexto. $\mathrm{O}$ fato de as mulheres escreverem sobre futebol em jornais é aqui compreendido como uma das formas possíveis de participar desse contexto. Mesmo que elas escrevam sobre um universo onde se considerem ausentes, como foi visto em algumas reportagens aqui analisadas, podemos dizer que essa ausência é uma forma de participação.

15 Seguindo nessa fala, o autor destaca que "não por acaso até as avós acompanham a copa!" (DAMO, 2006a, p. 42).

1638 reportagens.

1745 reportagens.

1826 reportagens.

19 Conflitos estes, podendo estar relacionados tanto entre regiões quanto dentro de uma própria região. Para aprofundar essa discussão ver Oliven (2006).

20 As reportagens desse grupo são, na grande maioria, coberturas de fatos que ocorreram na Copa. Mas o que chama a atenção é que nenhuma delas cobria os acontecimentos da seleção brasileira, mas sim das outras seleções participantes do evento.

21 Nesse artigo de Simoni Lahud Guedes, é discutido como as propagandas feitas no período da Copa do Mundo de 2002, tanto no Brasil como na Argentina, envolviam as diferenças entre esses dois países.

22 Publicada dois dias após a goleada de 6 x 0 da Argentina sobre a Sérvia e Montenegro.

23 Na reportagem "Irregular, Zidane faz $1^{\circ}$ gol na Copa e ressuscita França”, publicada no dia 28/06/2006, Mariana Barros (2006, p. 
D8) escreve: "Zidane, algoz do Brasil na decisão do Mundial de 1998, comemora seu gol, o terceiro da França contra a Espanha". Fica claro que a maneira que ela encontrou para identificar quem era o jogador Zidane foi relatar algum fato que envolvia a seleção brasileira.

24 Nesse terceiro grupo de reportagens, caracterizado pelos relatos de experiências das articulistas, chama atenção a maneira como as autoras se colocam em relação não só à Copa do Mundo da Alemanha, mas também ao universo do futebol. Fica visível que há, pelo menos, dois pólos opostos em que essas mulheres se posicionam para escreverem sobre suas vidas e a Copa. De um lado, podemos identificar aquelas que deixam claro em suas reportagens que "Nunca entendi um ovo de futebol. Nada. Nadica" (Trecho retirado da reportagem escrita por Cíntia Moscovich, "Sono redondo", publicada no dia 28 de maio de 2006, p. D6). E do lado oposto encontramos as que, ao escreverem sobre suas vidas e a Copa, simplesmente falam sobre o jogo, as jogadas e suas opiniões sobre elas, suas reivindicações aos atletas e à comissão técnica que compõem nossa seleção. Como, por exemplo, Soninha (2006c, p. D7), que, ao publicar a crônica "O VT é burro" no dia 20 de junho de 2006, escreve: "Eu vi o jogo do Brasil no campo. Vi Kaká e Robinho cansarem de pedir a bola-desmarcados, bem posicionados - e não receber".

25 Soninha faz os comentários referindo-se aos jogos-treinos que a seleção vinha fazendo para se preparar para a Copa do mundo.

26 O entrevistado foi o "senegalês Doudou Diene, relator especial da Comissão de Direitos Humanos da ONU sobre Formas Contemporâneas de Racismo" (LAJOLO, 2006, p. 9).

27 Segundo especificações trazidas na Folha de São Paulo, "Heloísa Reis é coordenadora do Grupo de Pesquisa de Futebol da Unicamp" (REIS, 2006, p. 9).

28 Apesar de compreender que era um jogo importante, ela não conseguiu assisti-lo, pois, após comer os preparados de sua mãe, pegou no sono.

\section{REFERÊNCIAS}

BARROS, M. Irregular, Zidane faz $1^{\circ}$ gol na Copa e ressuscita França. Folha de São Paulo, São Paulo, 28 jun. 2006. p. D8. 
BOTELHO, R. Copa do mundo inspira coquetéis tropicais. Folha de São Paulo, São Paulo, 1 jun. 2006. p. E5.

DAMO, A. S. O ethos capitalista e o espírito das copas. In: GASTALDO, É. L.; GUEDES, S. L. (Orgs.). Nações em campo: Copa do Mundo e identidade nacional. Niterói: Intertexto, 2006a. p. 39-72.

. Senso de jogo. In: Esporte e Sociedade - Revista Digital, n. 1, nov. 2005 / fev. 2006b. Disponível em: <http://www.lazer.eefd.ufrj.br/ espsoc/>. Acesso em 9 jul. 2006.

FERREIRA, C. T. Jogos mal começaram, mas já irritam a tribo dos que odeiam o campeonato. Folha de São Paulo, São Paulo, 10 jun. 2006. p. C4.

GANCIA, B. A seleção é a cara do Congresso. Folha de São Paulo, São Paulo, 7 jul. 2006. p. C2.

GASTALDO, É. L.; GUEDES, S. L. De pátrias e de chuteiras. In:

(Orgs.). Nações em campo: Copa do Mundo e identidade nacional. Niterói: Intertexto, 2006. p. 7-12.

GASTALDO, É. L. A pátria na "imprensa de chuteiras": futebol, mídia e identidades brasileiras. In: GASTALDO, É. L.; GUEDES, S. L. (Orgs.). Nações em campo: Copa do Mundo e identidade nacional. Niterói: Intertexto, 2006. p. 87-102.

GUEDES, S. L. De criollos e capoeiras: notas sobre futebol e identidade nacional na Argentina e no Brasil. In: GASTALDO, É. L.; GUEDES, S. L. (Orgs.). Nações em campo: Copa do Mundo e identidade nacional. Niterói: Intertexto, 2006. p. 127-146.

HOBSBAWM, E. Introdução: a invenção das tradições; A produção em massa das tradições. In: HOBSBAWM, E.; RANGER, T. A invenção das tradições. Rio de Janeiro: Paz e Terra, 1984. p. 9-23; 271-316.

LAGE, J. Copa do mundo alavanca o desempenho econômico. Folha de São Paulo, São Paulo, 21 maio 2006. p. B13.

LAJOLO, M. Para não dizer que só falei das flores: o espinho do racismo. Folha de São Paulo, São Paulo, 4 jun. 2006. Caderno futebologia, p. 9. 
LEÃO, D. Dois mundos. Folha de São Paulo, São Paulo, 11 jun. 2006. p. C2.

MARREIRO, F. Buenos Aires vibra e dá fim à humildade. Folha de São Paulo, São Paulo, 17 jun. 2006a. p. D7.

. País exalta Ronaldinho e transfere o favoritismo. Folha de São Paulo, São Paulo, 10 jun. 2006b. p. D7.

MATTOS, A. Onipresença ameaça ataque de Ronaldinho na mídia. Folha de São Paulo, São Paulo, 7 jun. 2006. p. B10.

MOSCOVICH, C. Sono redondo. Folha de São Paulo, São Paulo, 28 maio 2006. p. D6.

MOURA, E. L. O futebol como área reservada masculina. In: DAOLIO, J. (Org.). Futebol, cultura e sociedade. Campinas, SP: Autores Associados, 2005. p. 131-147.

OLIVEN, R. G. A parte e o todo: a diversidade cultura no Brasil-nação. 2. ed. rev. e ampl. Petrópolis, RJ: Vozes, 2006.

ORTIZ, R. Modernidade-mundo e identidade. In: . Um outro território: ensaios sobre a mundialização. São Paulo: Olho d'Água, [s.d]. p. 67-89.

REIS, Heloísa. Para não dizer que só falei das flores: $\mathrm{O}$ cravo da violência. Folha de São Paulo. São Paulo, 4 jun. 2006. Caderno futebologia, p. 9.

SONINHA. Favoritismo x Já Ganhou. Folha de São Paulo. São Paulo, 30 maio 2006a. p. D3.

. Vagas em disputa? In: Folha de São Paulo. São Paulo, 06 jun. 2006b. p. D7.

D7.

. O VT é burro. Folha de São Paulo. São Paulo, 20 jun. 2006c. p. D7.

. E agora, Parreira? Folha de São Paulo. São Paulo, 23 jun. 2006d. p.

SOUZA, C. V. de. A Folha de São Paulo e o "país do futebol": narrativas jornalísticas da nação e o debate de 1997 sobre o futebol brasileiro. 
História: Questões \& Debates, Curitiba, ano 20, n. 39, p. 65-90, jan./ dez. 2003.

STIGGER, M. P. Esporte, lazer e estilos de vida: um estudo etnográfico. Campinas, SP: Autores Associados, 2002.

Recebido: 27 de outubro de 2006 Aprovado: 9 de novembro de 2006

Endereço para correspondência:

Raquel da Silveira

Barão do Amazonas, 1236 - 303 Porto Alegre - Rio Grande do Sul CEP 90670-001

E-mail: raqkarate@hotmail.com 